\title{
Multi-response optimization of EDM drilling parameters of the Nitinol SMA
}

\section{Otimização de múltiplas respostas de parâmetros de perfuração EDM do}

\section{Nitinol SMA}

Article Info:

Article history: Received 2021-07-20 / Accepted 2021-08-16/ Available online 2021-08-16 doi: 10.18540/jcecvl7iss4pp13007-01-17e

\author{
Amiya Kumar Sahoo \\ ORCID: https://orcid.org/0000-0001-6572-4438 \\ Jaypee University of Engineering and Technology, India \\ E-mail: amiya.badani@gmail.com \\ Praneet Pandey \\ ORCID: https://orcid.org/0000-0003-1070-1727 \\ Jaypee University of Engineering and Technology, India \\ E-mail: pandeypraneet@,gmail.com \\ Dhananjay R Mishra \\ ORCID: https://orcid.org/0000-0002-5107-0012 \\ Jaypee University of Engineering and Technology, India \\ E-mail: dm30680@gmail.com
}

\section{Resumo}

A demanda por Nitinol (SMA) está aumentando rapidamente para várias aplicações. Com o objetivo de otimizar os parâmetros de controle de EDM, 46 experimentos foram concluídos em seis corpos de prova de 6,156 mm de espessura usando a máquina de perfuração EDM Sparkonix. Corrente (I), tensão (V), tempo de carga (TON), tempo de descarga (T $\mathrm{T}_{\mathrm{OFF}}$ ) e pressão dielétrica (DP) foram tomados como parâmetros de controle de entrada. A otimização de índice único da taxa de remoção de material (MRR), taxa de desgaste da ferramenta (TWR) e grau de rosqueamento (DoT) são avaliados usando o grau relacional cinza (GRG). Contribuições de parâmetros de controle individuais são avaliadas usando Taguchi e ANOVA. Os parâmetros de controle de entrada ótimos obtidos foram usados para o experimento de confirmação, e o resultado obtido dá uma boa concordância com ele. V e T ON são encontrados como os parâmetros mais significativos. Os valores máximo e mínimo de MRR, TWR e DoT foram registrados como 0,0277 e 0,0074 g / min, 0,0177 e 0,0033 g / min e 0,032 e 0,01 radianos, respectivamente. MRR, TWR e DoT melhoraram em 49,1, 4,5 e $43,3 \%$, respectivamente.

Palavras-chave: EDM. Nitinol. Eletrodo tubular rotativo de cobre. GRA. Taguchi.

\begin{abstract}
The demand for Nitinol (SMA) is increasing rapidly for various applications. With the aim of optimum control parameters of EDM, 46 experiments completed on six specimens of $6.156 \mathrm{~mm}$ thickness using Sparkonix EDM drill machine. Current (I), voltage (V), charging-time (TON), discharging-time $\left(\mathrm{T}_{\mathrm{OFF}}\right.$ ), and dielectric pressure (DP) were taken as input control parameters. Singleindexed optimization of material removal rate (MRR), tool-wear rate (TWR), and degree of tapperness (DoT) are evaluated using gray relational grade (GRG). Individual control-parameter contributions are evaluated using Taguchi and ANOVA. The obtained optimal input control parameters were used for the confirmation experiment, and the obtained result gives good agreement to it. $\mathrm{V}$ and $\mathrm{T}_{\mathrm{ON}}$ are found as the most significant parameters. Maximum and minimum values of MRR, TWR, and DoT have been recorded as $0.0277 \& 0.0074 \mathrm{~g} / \mathrm{min}, 0.0177 \& 0.0033 \mathrm{~g} / \mathrm{min}$, and $0.032 \& 0.01$ radians respectively. MRR, TWR, and DoT improved by $49.1,4.5$, and $43.3 \%$, respectively.
\end{abstract}

Keywords: EDM. Nitinol. Copper rotary tubular electrode. GRA. Taguchi. 


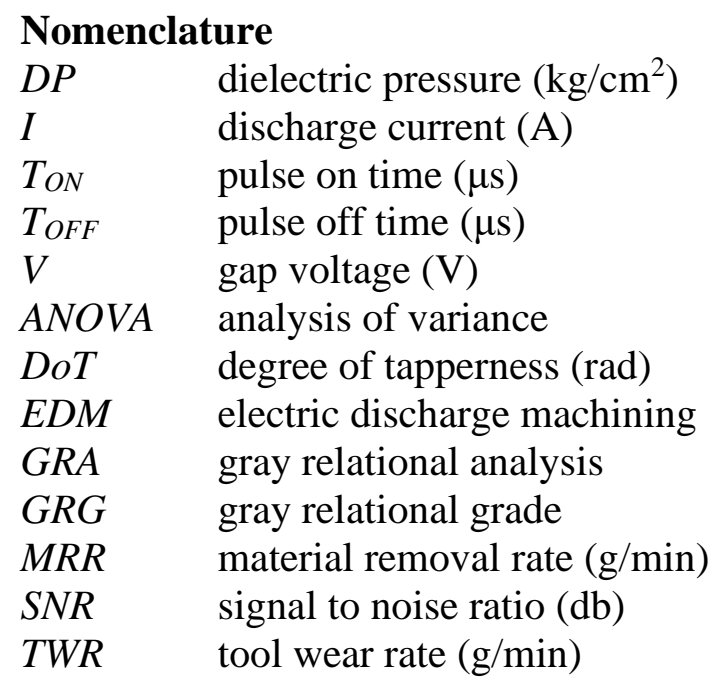

\section{Introduction}

The EDM machining process has become famous and vital due to its numerous applications in different industries (viz. aerospace, automotive, power plant) and its ability to produce precise, axisymmetry and arbitrary shapes electrically conductive materials. As EDM has high initial and operating costs, it needs to be operated on the parameters that give the desired unique quality at minimum manufacturing time and cost for shortening payback.

Productivity and quality will get affected due to the selection of inappropriate control parameters; hence, the choice of optimal control parameters is one of the significant concerns for the manufacturing industry. The selection of optimum control parameters depends on the machine and material. The most crucial process control parameters that affect the EDM drilling process largely are dielectric pressure, gap voltage, discharge current, and type of electrode. Many researchers have reported optimising electrode wear rate, material removal rate, hole circularity, and taper angle for different materials on EDM (P. Sharma et al., 2014; Shin et al., 2019). Process selection and evaluation of non-traditional machining using the generation of the standard throughhole in glass and deep through cavities in titanium with the integration of roughness number by using multi-attribute border approximation area comparison method for seventeen different machines has been reported by Chakraborty et al. (2019).

Effect on mechanical properties of Nitinol (medical grade) and characterization (arcing phenomena) in micro-EDM has been reported by Mwangi et al. (2020). They have reported that the three peak-transformation behaviour arcing phenomena will play a vital role, and thermal damage caused by arcing enhances residual strain, minimizes elongation to failure, machining accuracy, and lower and upper plateau stresses. Liu et al. (2018) conducted wire-EDM on Nitinol SMA and found that a thin white layer with less residual tensile stress slows down the crack formation and propagation, enhancing fatigue life. K. E. Ch. Vidyasagar et al. (2020) reported improvement of corrosion resistance of Nitinol in the presence of simulated body fluid by depositing titanium oxides on its surface. Nguyen HuuPhan et al. (2020) reported an evenly distributed white layer using titanium power with the dielectric fluid and copper electrode as the electrode's electrical and thermal conductivity, and the powder affects the surface quality.

Himadri Majumder and Kalipada Maity (2018) optimized process parameters of WEDM of Nitinol for surface roughness and micro-hardness by using general regression neural network and fuzzy logic. Shape memory behaviour of Nitinol is a thermo-mechanical phase transformation between the martensitic and austenitic phases. In micro-EDM, the high energy dissipated for material removal can significantly change the SMA phase transformation behaviour to reduce thermal hysteresis (Mwangi et al., 2018). Kannan et al. (2018) compared different post-heat 
treatment processes on the laser-welded Nitinol sheet and found that laser processing has a lower difference in phase transformation temperature due to self-quenching and controlled heat input. Major input variable factors influencing the performance characteristics of WEDM for Nimonic-75 alloy based on principal component evaluation and Taguchi and ANOVA analysis have been reported by Sonawane and Kulkarni (2018). They reported improvement in the composite primary component from 1.2013 to 1.2443 in multiple-response at optimal machining process parameters. Optimization of process parameters for powder mixed electro-discharge machining using the technique for order of preference by similarity to ideal solution (TOPSIS) and GRA has been reported by Tripathy and Tripathy (2016).

Md Al-Amin et al. (2020) reviewed power mixed EDM for biomedical applications to improve surface quality by depositing some superior metal to enhance the material's micro-hardness and corrosion resistance property. Singh et al. (P. N. Singh et al., 2004) have reported optimization of EDM parameter by using GRA for machining of Al - 10\% SiCp composite. Lin and Lin (2002) have utilized GRA to optimise EDM process parameters using the orthogonal array considering gray relational grade as a performance index. Sudhir Kumar et al. (S. Kumar et al., 2020) reported multi-performance characteristics of die-sinking EDM improved using Taguchi-GRA technique and growth of 0.0860 in GRG on AISI420 stainless steel.

Ramver Singh et al. (2020) investigated EDMed deep micro-holes on Ti-6Al-4V alloy and reported the size of debris reduced and the increase in the size of gas bubbles along with the depth of the hole. Ahmed et al. (2019) have reported the deep-hole drilling method of Inconel 718 material to analyze the effectiveness of coolant pressure and rotational speed on the hole's straightness during the process using Euler-Bernoulli beam theory.

Ankit Sharma et al. (2020) reported deposition of Inconel 718 on the surface of aluminium alloy 7075 using the EDM process, which enhanced the micro-hardness to 1.5 to 2.5 times. A detailed review of the micro and conventional EDM machining process for tungsten carbide and its composite material has been reported by Jahan et al. (2011). Kumar et al. (2020) extensively reviewed the micro-EDM process concerning discharge power and dielectric circulation and its sustainability system for green manufacturing. The machinability of Nitinol shape memory alloy (SMA) is inadequate for its lower thermal conductivity and work hardening effect leading to higher cutting zone temperature in conventional machining conditions (A. Sharma \& Yadava, 2018).

Therefore, unconventional methods of material removal supersede traditional methods. EDM drilling method can produce micro-holes on hard to cut materials such as Nitinol SMA. In this paper, multi-response optimization of variable control parameters for EDM drilling operation using GRA assisted Taguchi on Nitinol is reported.

\section{Material and methods}

The two-phased methodology selected to carry out the optimization of variable control parameters of the machining operation of Nitinol SMA is shown in Figure 1. In the first phase, the selection of machining parameters, pilot experiments, and design of experiments using BoxBehnken design (BBD) was carried out. Whereas in the second phase, mathematical modelling, validation of the developed model, ANOVA analysis, confirmation experiments based on optimal results, and percentage contribution of control parameters has been carried out with the help of Taguchi assisted gray relation analysis.

Nitinol is a well-recognized material for its superelasticity and biocompatibility as it has numerous applications in different industries. The material Nitinol used for the experimentation chemically consists of $49.1 \% \mathrm{Ni}$ and $50.9 \% \mathrm{Ti}$. The physical and mechanical properties of Nitinol SMA are tabulated in Table 1, respectively. 
Table 1 - Physical and mechanical Properties of Nitinol.

\begin{tabular}{l|l}
\hline Melting Temperature & $1240-1310{ }^{\circ} \mathrm{C}$ \\
\hline Resistivity (high temperature state) & $82 \mu \Omega-\mathrm{cm}$ \\
\hline Resistivity (low temperature state) & $76 \mu \Omega-\mathrm{cm}$ \\
\hline Thermal Conductivity & $0.1 \mathrm{~W} / \mathrm{cm} /{ }^{\circ} \mathrm{C}$ \\
\hline Heat Capacity & $0.077 \mathrm{cal} / \mathrm{gm} /{ }^{\circ} \mathrm{C}$ \\
\hline Latent Heat & $5.78 \mathrm{cal} / \mathrm{gm}$ \\
\hline Magnetic Susceptibility (high temperature) & $3.8 \mu \mathrm{emu} / \mathrm{gm}$ \\
\hline Magnetic Susceptibility (low temperature) & $2.5 \mu \mathrm{emu} / \mathrm{gm}$ \\
\hline Tensile Strength & Austenite: $195-690 \mathrm{MPa}$ \\
\hline Young's Modulus & Martensite: $70-140 \mathrm{MPa}$ \\
\hline Density & Austenite: $83 \mathrm{GPa}$ \\
\hline & Martensite: $28-41 \mathrm{GPa}$ \\
\hline
\end{tabular}

Phase I

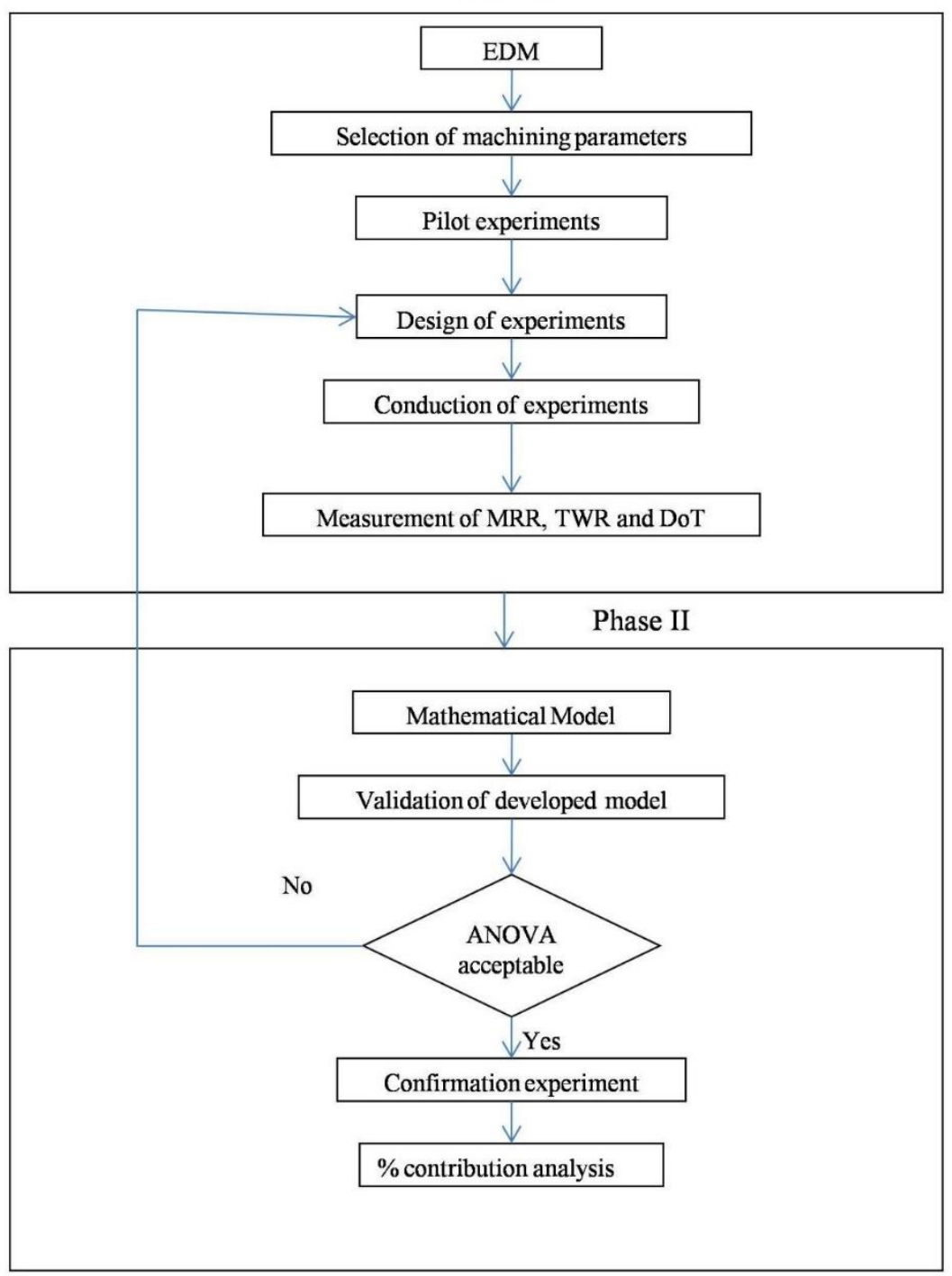

Figure 1 - Phase diagram of the methodology. 
The machinability of Nitinol is low due to its mechanical and physical properties. Hence nonconventional machining processes have mostly been taken into account for different material removal operations. All designed experiments were carried out of this study using Sparkonix EDM Drill Speed I machine. Its actual photograph is shown in Figure 2. Technical specifications and details of the EDM machine are tabulated in Table 2. The machine's process parameters have ten steps to control gap voltage, pulse-on time, and pulse-off time, whereas the discharge current has 25 -steps of one ampere each.

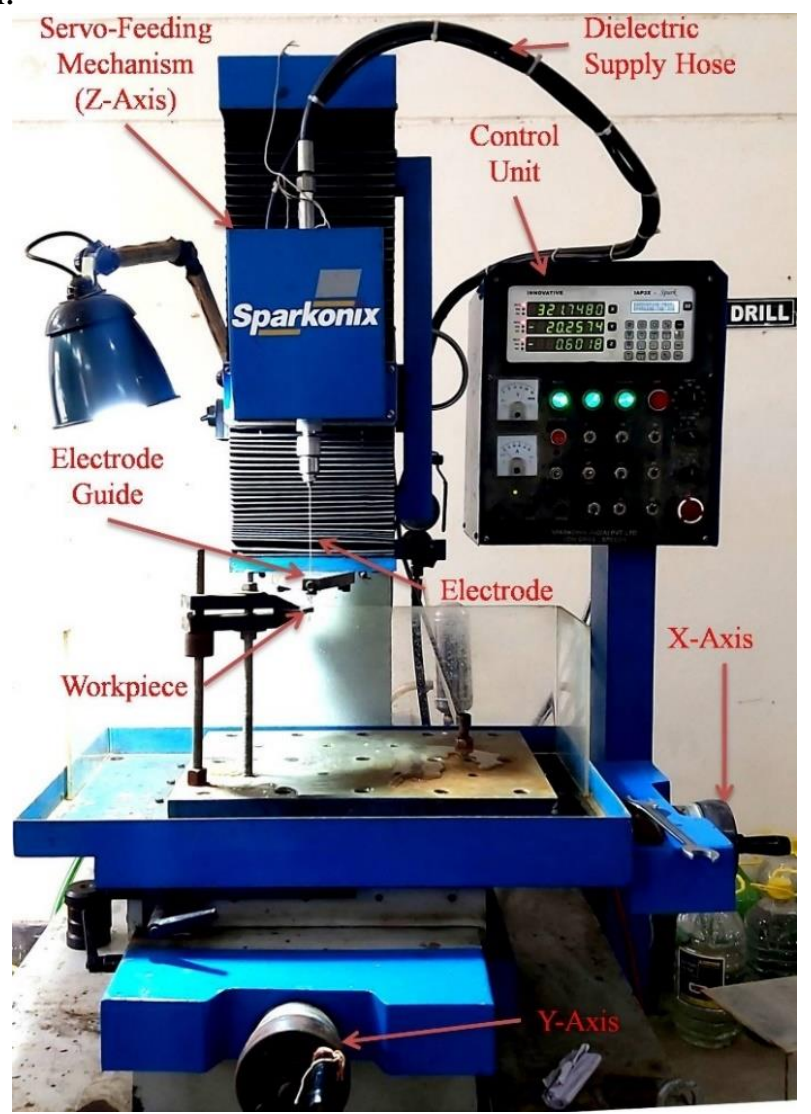

Figure 2 - Actual photograph of Sparkonix EDM Drill Speed I.

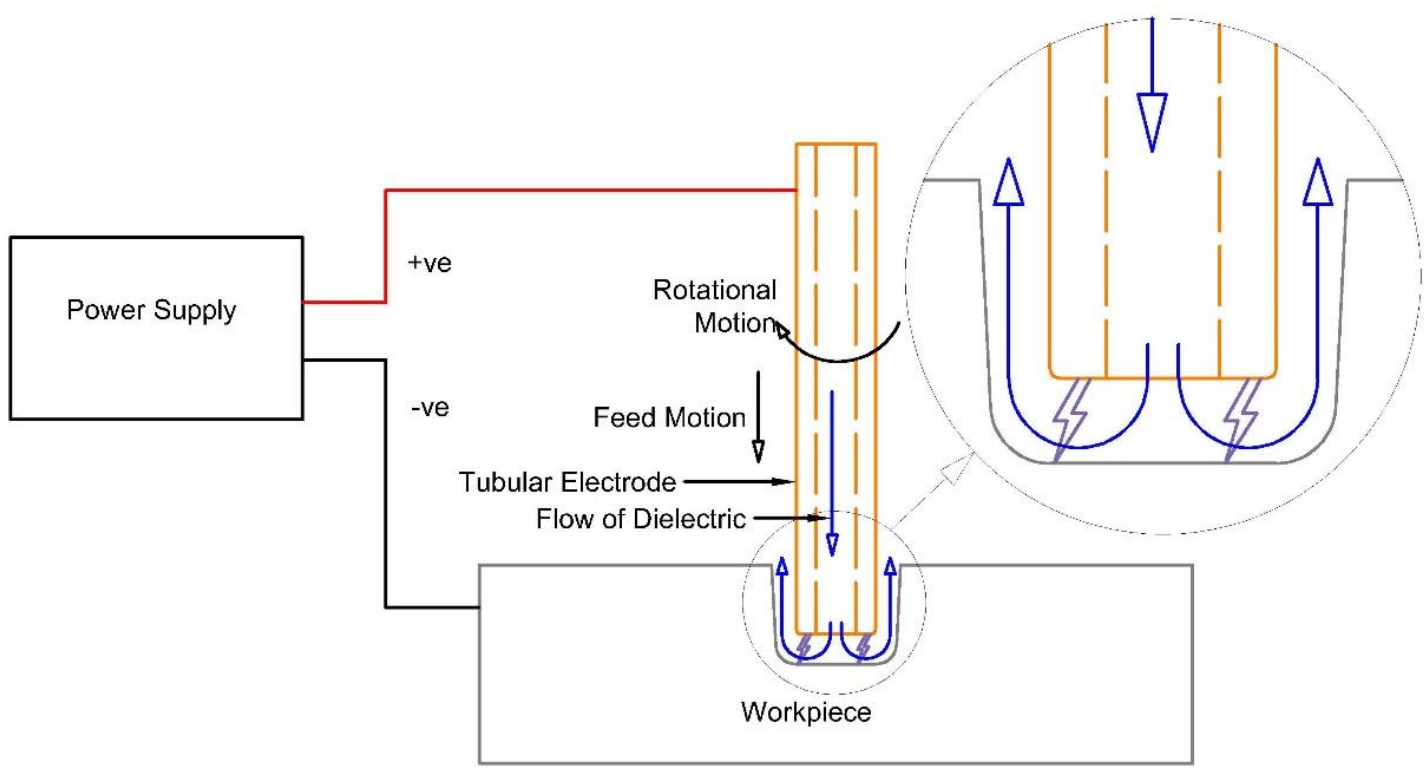

Figure 3 - Schematic of EDM drilling process. 
Table 2 - Technical specifications of Sparkonix EDM Drill Speed I.

\begin{tabular}{ccc}
\hline Sl. No. & Parameter & Range \\
\hline 1 & Gap Voltage & $10-100 \mathrm{~V}$ \\
2 & Discharge Current & $1-25 \mathrm{~A}$ \\
3 & Pulse-on Time & $1-10 \mu \mathrm{s}$ \\
4 & Pulse-off Time & $1-10 \mu \mathrm{s}$ \\
5 & Flushing Pressure & $\mathrm{Up} \mathrm{to} 100 \mathrm{~kg} / \mathrm{cm}^{2}$ \\
\hline
\end{tabular}

The EDM drilling operation would be well understood in Figure 3. The machine has a servo feeding mechanism for the electrode, controlled by the servo reference voltage to maintain the interelectrode gap. Pilot experiments have been carried out for deciding the different levels of variable control parameters of EDM. Three different current, gap voltage, pulse-on \& -off times, and dielectric pressure, are selected and tabulated in Table 3 based on pilot experiments results. Design of experiments reduces the cost and time of experimentation by reducing the redundant combinations of experiments of the full-factorial design and does not compromise the response's quality. BBD is suitable for the nonlinear behaviour of the response, which reduces the number of experiments compared to the full-factorial design and makes the experimentation economical. In the BBD design, a total of forty-six experiments with six replications of the centre point for five input parameters (viz. discharge current, gap voltage, pulse-on \& -off times, and dielectric pressure) was carried out using Minitab 17 software.

Table 3 - EDM drilling process parameters with their levels.

\begin{tabular}{lccccc}
\hline Control Factors & Unit & Notation & Level 1 & Level 2 & Level 3 \\
\hline Current & Ampere & $\mathrm{I}$ & 12 & 17 & 22 \\
Gap Voltage & Voltage & $\mathrm{V}$ & 40 & 50 & 60 \\
Pulse on time & $\mu \mathrm{s}$ & $\mathrm{T}_{\mathrm{ON}}$ & 2 & 4 & 6 \\
Pulse off time & $\mu \mathrm{s}$ & $\mathrm{T}_{\mathrm{OFF}}$ & 5 & 7 & 9 \\
Dielectric Pressure & $\mathrm{Kg} / \mathrm{cm}^{2}$ & $\mathrm{DP}$ & 50 & 75 & 100 \\
\hline
\end{tabular}

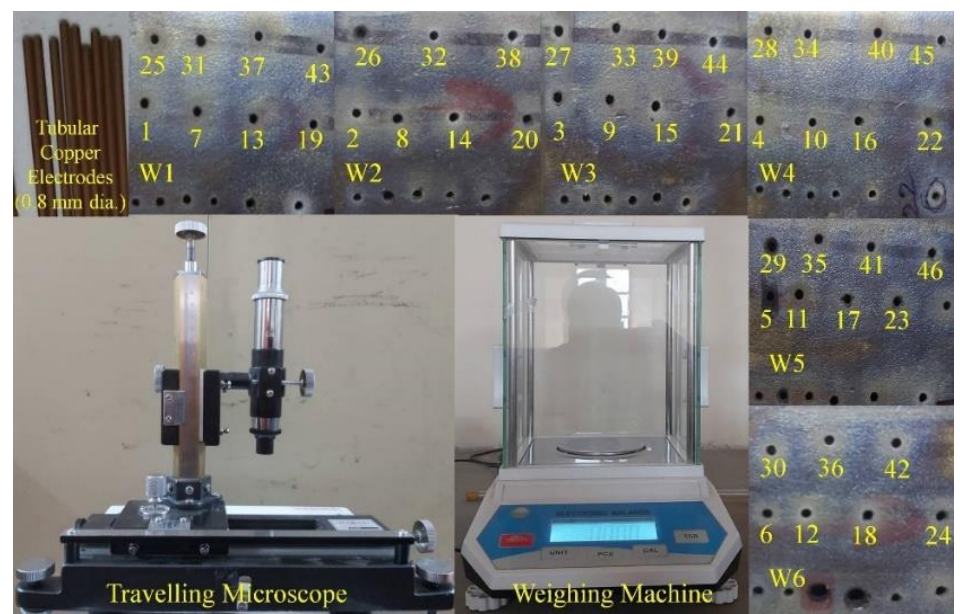

Figure 4 - Actual photographs of copper electrodes, workpieces, electronic weighing machine, and travelling microscope.

Six specimens of size $35 \times 35 \mathrm{~mm}^{2}$ with a uniform thickness of $6.156 \mathrm{~mm}$ with a variation of $0.001 \mathrm{~mm}$ were used for the experimentation process of EDM drilling with the help of tubular copper electrodes of $0.8 \mathrm{~mm}$ diameter. An electronic balance with $0.001 \mathrm{~g}$ least count has been used to measure the workpiece's weight and electrode before and after each experiment. The top and bottom diameters of each hole were measured for four different orientations of the hole with the help of a travelling microscope $(0.01 \mathrm{~mm}$ least count), and the average values were recorded at the end of every experiment. Actual photographs of copper electrodes, workpieces, electronic weighing 
machine, and travelling microscope are shown in Figure 4, along with experiment numbers of each hole. Process performance parameters of EDM one can get using Equation 1, 2 \& 3.

$$
\begin{aligned}
& M R R=\frac{(\text { inital }- \text { final }) \text { weitht of } \text { work material }}{\text { machining time } \times \text { desnity of work material }} \\
& T W R=\frac{(\text { inital }- \text { final }) \text { weitht of electrode }}{\text { machining time } \times \text { desnity of electrode }} \\
& \text { DoT }=\tan ^{-1}\left[\frac{D_{t}-D_{b}}{2 H}\right]
\end{aligned}
$$

$D_{t}$ and $D_{b}$ are the average top and bottom diameters, respectively, and $H$ is the hole's depth. Factors and their levels, along with the measured values of MRR, TWR, and DoT, are tabulated in Table 4.

\begin{tabular}{|c|c|c|c|c|c|c|c|c|c|c|c|c|c|}
\hline \multirow[t]{2}{*}{$\begin{array}{l}\text { Ex. } \\
\text { No. }\end{array}$} & \multicolumn{5}{|c|}{ Factors and their levels } & \multicolumn{3}{|c|}{ Responses } & \multicolumn{3}{|c|}{$\begin{array}{c}\text { Grey Relational } \\
\text { Coefficient }\end{array}$} & \multirow[t]{2}{*}{ GRG } & \multirow[t]{2}{*}{ Order } \\
\hline & $\mathbf{I}$ & $\mathbf{V}$ & ToN & ToFF & DP & MRR & TWR & DoT & MRR & TWR & DoT & & \\
\hline 1 & 12 & 50 & 4 & 7 & 100 & 0.0110 & 0.0067 & 0.0171 & 0.3786 & 0.6820 & 0.6086 & 0.5564 & 29 \\
\hline 2 & 17 & 50 & 2 & 5 & 75 & 0.0128 & 0.0047 & 0.0284 & 0.4050 & 0.8364 & 0.3784 & 0.5399 & 32 \\
\hline 3 & 22 & 50 & 4 & 7 & 100 & 0.0195 & 0.0091 & 0.0130 & 0.5535 & 0.5538 & 0.7777 & 0.6283 & 13 \\
\hline 4 & 17 & 50 & 4 & 7 & 75 & 0.0149 & 0.0067 & 0.0146 & 0.4419 & 0.6803 & 0.6999 & 0.6074 & 18 \\
\hline 5 & 17 & 50 & 6 & 5 & 75 & 0.0196 & 0.0065 & 0.0146 & 0.5552 & 0.6929 & 0.6999 & 0.6493 & 8 \\
\hline 6 & 12 & 50 & 4 & 7 & 50 & 0.0076 & 0.0044 & 0.0154 & 0.3364 & 0.8729 & 0.6666 & 0.6253 & 14 \\
\hline 7 & 12 & 50 & 4 & 9 & 75 & 0.0084 & 0.0041 & 0.0211 & 0.3455 & 0.9050 & 0.4999 & 0.5835 & 24 \\
\hline 8 & 17 & 50 & 2 & 7 & 100 & 0.0075 & 0.0053 & 0.0284 & 0.3347 & 0.7805 & 0.3784 & 0.4979 & 40 \\
\hline 9 & 22 & 50 & 4 & 5 & 75 & 0.0243 & 0.0084 & 0.0300 & 0.7466 & 0.5888 & 0.3590 & 0.5648 & 25 \\
\hline 10 & 17 & 40 & 2 & 7 & 75 & 0.0094 & 0.0040 & 0.0252 & 0.3572 & 0.9100 & 0.4242 & 0.5638 & 27 \\
\hline 11 & 17 & 40 & 4 & 7 & 50 & 0.0114 & 0.0046 & 0.0138 & 0.3838 & 0.8539 & 0.7368 & 0.6582 & 7 \\
\hline 12 & 17 & 60 & 4 & 5 & 75 & 0.0277 & 0.0128 & 0.0268 & 1.0000 & 0.4329 & 0.4000 & 0.6110 & 16 \\
\hline 13 & 17 & 50 & 6 & 7 & 50 & 0.0147 & 0.0036 & 0.0268 & 0.4390 & 0.9683 & 0.4000 & 0.6024 & 20 \\
\hline 14 & 17 & 60 & 4 & 7 & 50 & 0.0178 & 0.0151 & 0.0300 & 0.5070 & 0.3794 & 0.3590 & 0.4151 & 44 \\
\hline 15 & 12 & 50 & 6 & 7 & 75 & 0.0114 & 0.0057 & 0.0106 & 0.3835 & 0.7536 & 0.9333 & 0.6901 & 2 \\
\hline 16 & 17 & 50 & 4 & 9 & 50 & 0.0091 & 0.0063 & 0.0227 & 0.3540 & 0.7108 & 0.4666 & 0.5105 & 38 \\
\hline 17 & 12 & 60 & 4 & 7 & 75 & 0.0171 & 0.0171 & 0.0187 & 0.4895 & 0.3442 & 0.5599 & 0.4645 & 42 \\
\hline 18 & 12 & 50 & 2 & 7 & 75 & 0.0098 & 0.0042 & 0.0268 & 0.3622 & 0.8912 & 0.4000 & 0.5511 & 30 \\
\hline 19 & 22 & 50 & 4 & 7 & 50 & 0.0181 & 0.0062 & 0.0276 & 0.5147 & 0.7114 & 0.3889 & 0.5383 & 33 \\
\hline 20 & 17 & 60 & 2 & 7 & 75 & 0.0126 & 0.0131 & 0.0268 & 0.4025 & 0.4252 & 0.4000 & 0.4092 & 45 \\
\hline 21 & 17 & 40 & 4 & 9 & 75 & 0.0074 & 0.0045 & 0.0187 & 0.3341 & 0.8630 & 0.5599 & 0.5857 & 23 \\
\hline 22 & 17 & 50 & 2 & 7 & 50 & 0.0107 & 0.0048 & 0.0268 & 0.3740 & 0.8290 & 0.4000 & 0.5343 & 34 \\
\hline 23 & 22 & 50 & 6 & 7 & 75 & 0.0164 & 0.0064 & 0.0097 & 0.4736 & 0.6980 & 1.0000 & 0.7239 & 1 \\
\hline 24 & 17 & 40 & 4 & 7 & 100 & 0.0143 & 0.0052 & 0.0122 & 0.4313 & 0.7933 & 0.8235 & 0.6827 & 3 \\
\hline 25 & 17 & 40 & 4 & 5 & 75 & 0.0144 & 0.0046 & 0.0154 & 0.4324 & 0.8475 & 0.6666 & 0.6489 & 9 \\
\hline 26 & 22 & 60 & 4 & 7 & 75 & 0.0222 & 0.0174 & 0.0171 & 0.6469 & 0.3392 & 0.6086 & 0.5316 & 35 \\
\hline 27 & 17 & 50 & 4 & 7 & 75 & 0.0156 & 0.0068 & 0.0235 & 0.4563 & 0.6736 & 0.4516 & 0.5271 & 36 \\
\hline 28 & 22 & 50 & 2 & 7 & 75 & 0.0175 & 0.0045 & 0.0325 & 0.4990 & 0.8616 & 0.3333 & 0.5646 & 26 \\
\hline 29 & 17 & 50 & 4 & 5 & 50 & 0.0174 & 0.0045 & 0.0260 & 0.4959 & 0.8610 & 0.4117 & 0.5895 & 22 \\
\hline 30 & 17 & 50 & 4 & 7 & 75 & 0.0203 & 0.0073 & 0.0122 & 0.5797 & 0.6423 & 0.8235 & 0.6818 & 4 \\
\hline 31 & 17 & 50 & 4 & 7 & 75 & 0.0157 & 0.0049 & 0.0317 & 0.4587 & 0.8225 & 0.3415 & 0.5409 & 31 \\
\hline
\end{tabular}

Table 4 - Values of MRR, TWR, and DoT and their GRCs, GRG, and order along with experimental process parameter. 


\begin{tabular}{c|c|c|c|c|c|c|c|c|c|c|c|c|c}
\hline 32 & 17 & 50 & 4 & 7 & 75 & 0.0124 & 0.0062 & 0.0300 & 0.3988 & 0.7157 & 0.3590 & 0.4912 & 41 \\
\hline 33 & 12 & 50 & 4 & 5 & 75 & 0.0112 & 0.0053 & 0.0284 & 0.3814 & 0.7814 & 0.3784 & 0.5137 & 37 \\
\hline 34 & 22 & 40 & 4 & 7 & 75 & 0.0208 & 0.0046 & 0.0325 & 0.5940 & 0.8534 & 0.3333 & 0.5936 & 21 \\
\hline 35 & 17 & 50 & 2 & 9 & 75 & 0.0075 & 0.0049 & 0.0317 & 0.3345 & 0.8218 & 0.3415 & 0.4992 & 39 \\
\hline 36 & 17 & 50 & 4 & 7 & 75 & 0.0083 & 0.0047 & 0.0138 & 0.3441 & 0.8414 & 0.7368 & 0.6407 & 12 \\
\hline 37 & 17 & 60 & 4 & 9 & 75 & 0.0186 & 0.0178 & 0.0300 & 0.5273 & 0.3333 & 0.3590 & 0.4065 & 46 \\
\hline 38 & 12 & 40 & 4 & 7 & 75 & 0.0074 & 0.0033 & 0.0211 & 0.3333 & 1.0000 & 0.4999 & 0.6111 & 15 \\
\hline 39 & 17 & 50 & 6 & 9 & 75 & 0.0147 & 0.0051 & 0.0146 & 0.4389 & 0.8059 & 0.6999 & 0.6483 & 10 \\
\hline 40 & 17 & 50 & 4 & 5 & 100 & 0.0191 & 0.0052 & 0.0154 & 0.5429 & 0.7913 & 0.6666 & 0.6669 & 6 \\
\hline 41 & 17 & 60 & 4 & 7 & 100 & 0.0211 & 0.0154 & 0.0146 & 0.6060 & 0.3741 & 0.6999 & 0.5600 & 28 \\
\hline 42 & 17 & 50 & 4 & 9 & 100 & 0.0145 & 0.0070 & 0.0122 & 0.4344 & 0.6647 & 0.8235 & 0.6408 & 11 \\
\hline 43 & 22 & 50 & 4 & 9 & 75 & 0.0153 & 0.0084 & 0.0130 & 0.4513 & 0.5866 & 0.7777 & 0.6052 & 19 \\
\hline 44 & 17 & 40 & 6 & 7 & 75 & 0.0152 & 0.0041 & 0.0154 & 0.4480 & 0.9036 & 0.6666 & 0.6727 & 5 \\
\hline 45 & 17 & 50 & 6 & 7 & 100 & 0.0218 & 0.0053 & 0.0260 & 0.6322 & 0.7833 & 0.4117 & 0.6091 & 17 \\
\hline 46 & 17 & 60 & 6 & 7 & 75 & 0.0203 & 0.0158 & 0.0244 & 0.5794 & 0.3667 & 0.4375 & 0.4612 & 43 \\
\hline
\end{tabular}

Mathematical modelling has been performed to establish the relationship between variable control parameters of EDM and response parameters (viz. MRR, TWR, and DoT).

Complicated interrelationships between designated performance characteristics are effectively analyzed with GRA's help as it gives an efficient solution to discrete uncertainty and multi-input data problems (Datta et al., 2008; Gautam \& Mishra, 2019). Data processing was carried out by normalizing the results obtained from the experimentation. It has been used for multiresponse optimization of MRR, TWR, and DoT. First, the performance characteristics were normalized: MRR has been normalized for larger the better using Equation 4, and TWR and DoT have been normalized for smaller the better using Equation 5.

For larger the better performance characteristic:

$x_{i}=\frac{y_{i}-\min \left(y_{i}\right)}{\max \left(y_{i}\right)-\min \left(y_{i}\right)}$

For smaller the better performance characteristic:

$x_{i}=\frac{\max \left(y_{i}\right)-y_{i}}{\max \left(y_{i}\right)-\min \left(y_{i}\right)}$

Where $y_{i}$ is the $i^{\text {th }}$ response, and $\max \left(y_{i}\right)$ and $\min \left(y_{i}\right)$ are the maximum and minimum values of the responses.

Before finding the value of gray relational coefficients (GRC) using Equation 7, the deviational sequences were evaluated using Equation 6, and gray relational grades (GRG) were assessed using Equation 8 tabulated and its order shown in Table 4.

$\Delta x_{i}=\max \left(x_{i}\right)-x_{i}$

$\xi_{i}=\frac{\min \left(\Delta x_{i}\right)+\zeta \max \left(\Delta x_{i}\right)}{\Delta x_{i}+\zeta \max \left(\Delta x_{i}\right)}$

Where $\Delta \mathrm{x}_{\mathrm{i}}$ is the deviation sequence and $\zeta=0.5$ (equal preference for all performance parameters).

Based on GRG, the overall evaluation of multi-performance characteristics is evaluated as GRG as a weighting sum of GRCs.

$\gamma_{i}=\frac{1}{n} \sum_{1}^{n} \xi_{i}$

Comparability sequence exerts over the reference sequence as GRG indicates the degree of influence, and its more immense value indicates that the quality of product complements the outstanding value.

Taguchi optimization technique is recognized for one response at a time approach. The multiresponse optimization using Taguchi was carried out with the assistance of GRA. Taguchi considers the signal to noise ratio (SNR) as the quality characteristic of the response. According to the quality 
characteristics, the SNRs (Taguchi \& Phadke, 1989) were calculated using Equation 9 or 10 and tabulated in Table 5.

For larger the better:

$\eta=-10 \times \log _{10} \frac{1}{n} \sum_{1}^{n}\left(\frac{1}{y_{i}^{2}}\right)$

For smaller the better:

$\eta=-10 \times \log _{10} \frac{1}{n} \sum_{1}^{n} y_{i}^{2}$

Table 5 - S/N ratio for various response parameters and GRG.

\begin{tabular}{|c|c|c|c|c|}
\hline \multirow[t]{2}{*}{ Ex. No. } & \multicolumn{4}{|c|}{ S/N Ratio } \\
\hline & MRR & TWR & DoT & GRG \\
\hline 1 & -39.1615 & 43.4957 & 35.3630 & -5.0919 \\
\hline 2 & -37.8776 & 46.5048 & 30.9276 & -5.3531 \\
\hline 3 & -34.1974 & 40.7786 & 37.7247 & -4.0362 \\
\hline 4 & -37.7934 & 44.1744 & 32.9920 & -4.8807 \\
\hline 5 & -34.1713 & 43.7137 & 36.7017 & -3.7505 \\
\hline 6 & -42.3359 & 47.1967 & 36.2322 & -4.0781 \\
\hline 7 & -41.4752 & 47.8006 & 33.5084 & -4.6797 \\
\hline 8 & -42.5127 & 45.4353 & 30.9276 & -6.0580 \\
\hline 9 & -32.3018 & 41.5498 & 30.4452 & -4.9618 \\
\hline 10 & -40.5358 & 47.8954 & 31.9812 & -4.9776 \\
\hline 11 & -38.8771 & 46.8359 & 37.1981 & -3.6334 \\
\hline 12 & -31.1461 & 37.8620 & 31.4384 & -4.2796 \\
\hline 13 & -36.6480 & 48.9940 & 31.4384 & -4.4021 \\
\hline 14 & -34.9818 & 36.3935 & 30.4452 & -7.6361 \\
\hline 15 & -38.8931 & 44.9137 & 39.5280 & -3.2212 \\
\hline 16 & -40.7751 & 44.0713 & 32.8649 & -5.8407 \\
\hline 17 & -35.3397 & 35.3397 & 34.5730 & -6.6598 \\
\hline 18 & -40.1811 & 47.5407 & 31.4384 & -5.1754 \\
\hline 19 & -34.8362 & 44.0842 & 31.1792 & -5.3789 \\
\hline 20 & -37.9863 & 37.6585 & 31.4384 & -7.7606 \\
\hline 21 & -42.5723 & 47.0093 & 34.5730 & -4.6465 \\
\hline 22 & -39.4286 & 46.3644 & 31.4384 & -5.4440 \\
\hline 23 & -35.7015 & 43.8168 & 40.2232 & -2.8069 \\
\hline 24 & -36.8944 & 45.6811 & 38.2852 & -3.3156 \\
\hline 25 & -36.8575 & 46.7158 & 36.2322 & -3.7571 \\
\hline 26 & -33.0883 & 35.1831 & 35.3630 & -5.4887 \\
\hline 27 & - & - & - & - \\
\hline 28 & -35.1399 & 46.9814 & 29.7684 & -4.9646 \\
\hline 29 & -35.2047 & 46.9702 & 31.7055 & -4.5901 \\
\hline 30 & - & - & - & - \\
\hline 31 & - & - & - & - \\
\hline 32 & - & - & - & - \\
\hline 33 & -39.0079 & 45.4523 & 30.9276 & -5.7856 \\
\hline 34 & -33.6557 & 46.8265 & 29.7684 & -4.5305 \\
\hline 35 & -42.5354 & 46.2259 & 29.9882 & -6.0340 \\
\hline 36 & - & - & - & - \\
\hline 37 & -34.6128 & 34.9989 & 30.4452 & -7.8179 \\
\hline 38 & -42.6580 & 49.5937 & 33.5084 & -4.2779 \\
\hline 39 & -36.6488 & 45.9240 & 36.7017 & -3.7649 \\
\hline
\end{tabular}




\begin{tabular}{l|l|l|l|l}
\hline 40 & -34.3579 & 45.6434 & 36.2322 & -3.5183 \\
\hline 41 & -33.5151 & 36.2395 & 36.7017 & -5.0359 \\
\hline 42 & -36.7948 & 43.1432 & 38.2852 & -3.8650 \\
\hline 43 & -36.2819 & 41.5002 & 37.7247 & -4.3621 \\
\hline 44 & -36.3765 & 47.7740 & 36.2322 & -3.4434 \\
\hline 45 & -33.2329 & 45.4885 & 31.7055 & -4.3066 \\
\hline 46 & -33.8389 & 36.0218 & 32.2659 & -6.7227 \\
\hline
\end{tabular}

Note: As there are six center points, the S/N ratio of Exp. No. 4 only is available

The significance of individual process parameters and their effects on the performance characteristics by decomposing the variance of the relative impact of different factors are evaluated using ANOVA as it indicates the impact of the control parameters on the GRA. The ANOVA analysis of GRA has been done, and the obtained results are tabulated in Table 6, which shows that the $\mathrm{V}$ and TON are the most significant process parameter.

Table 6 - Analysis of variance of GRG.

\begin{tabular}{l|c|c|c|c|c}
\hline Source & SS & DF & Mean Square & F-value & p-value \\
\hline Model & 0.1814 & 20 & 0.0091 & 2.71 & 0.0098 \\
\hline $\mathbf{A ~ ( I ) ~}$ & 0.0015 & 1 & 0.0015 & 0.4456 & 0.5105 \\
\hline B (V) & 0.0837 & 1 & 0.0837 & 24.99 & $<0.0001$ \\
\hline C (ToN) & 0.0503 & 1 & 0.0503 & 15.01 & 0.0007 \\
\hline D (ToFF) & 0.0058 & 1 & 0.0058 & 1.73 & 0.2006 \\
\hline E (DP) & 0.0085 & 1 & 0.0085 & 2.53 & 0.1240 \\
\hline AB & 0.0018 & 1 & 0.0018 & 0.5336 & 0.4719 \\
\hline AC & 0.0001 & 1 & 0.0001 & 0.0304 & 0.8630 \\
\hline AE & 0.0002 & 1 & 0.0002 & 0.0644 & 0.8017 \\
\hline BC & 0.0063 & 1 & 0.0063 & 1.88 & 0.1821 \\
\hline BD & 0.0008 & 1 & 0.0008 & 0.2423 & 0.6269 \\
\hline BE & 0.0050 & 1 & 0.0050 & 1.49 & 0.2337 \\
\hline CD & 0.0036 & 1 & 0.0036 & 1.08 & 0.3085 \\
\hline CE & 0.0004 & 1 & 0.0004 & 0.1172 & 0.7349 \\
\hline DE & 0.0005 & 1 & 0.0005 & 0.1388 & 0.7126 \\
\hline $\mathbf{A}^{\mathbf{2}}$ & 0.0007 & 1 & 0.0007 & 0.2092 & 0.6513 \\
\hline $\mathbf{B}^{\mathbf{2}}$ & 0.0007 & 1 & 0.0007 & 0.1980 & 0.6601 \\
\hline $\mathbf{C}^{\mathbf{2}}$ & 0.0081 & 1 & 0.0081 & 2.42 & 0.1324 \\
\hline $\mathbf{D}^{\mathbf{2}}$ & 0.0000 & 1 & 0.0000 & 0.0107 & 0.9183 \\
\hline $\mathbf{E}^{\mathbf{2}}$ & 0.0000 & 1 & 0.0000 & 0.0090 & 0.9252 \\
\hline Residual & 0.0003 & 1 & 0.0003 & 0.1000 & 0.7544 \\
\hline Lack of Fit & 0.0838 & 25 & 0.0034 & & \\
\hline Pure Error & 0.0567 & 20 & 0.0028 & 0.5253 & 0.8613 \\
\hline Total & 0.0270 & 5 & 0.0054 & & \\
\hline & 0.2651 & 45 & & & \\
\hline
\end{tabular}




\section{Results and discussions}

Interaction and main effect plots for MRR are shown in Figure $5 \& 6$, respectively. It is evident that by increasing the discharge current, MRR increases to an average value of $0.0193 \mathrm{~g} / \mathrm{min}$ due to the liberation of higher energy in the spark gap, which raises melting and evaporation of the workpiece material. The behaviour of gap voltage on MRR is the same as that of the discharge current, and it reaches an average value of $0.0197 \mathrm{~g} / \mathrm{min}$, as enhancement in the gap voltage leads to the rise in heat intensity. MRR increases to an average of $0.0168 \mathrm{~g} / \mathrm{min}$ with a surge in $\mathrm{T}_{\mathrm{ON}}$, whereas $\mathrm{T}_{\mathrm{OFF}}$ has a reverse impact on the MRR; its average value falls from $0.183-0.0119 \mathrm{~g} / \mathrm{min}$. $\mathrm{T}_{\mathrm{ON}}$ and $\mathrm{T}_{\mathrm{OFF}}$ indicate the sparking rate; when the sparking rate rises, more heat will carry from one spark to the other, which increases the MRR. The influence of dielectric pressure DP has a direct impact on MRR. By increasing DP, efficient flushing of the molten metal occurs, which increases the average value of MRR to $0.0161 \mathrm{~g} / \mathrm{min}$. The discharge current is the significant control variable parameter for maximizing MRR.

Figure $7 \& 8$ show the interaction and main effect plots for TWR, respectively. These figures indicate that the TWR increases to the average of $0.0081 \mathrm{~g} / \mathrm{min}$ by increasing the discharge current. It is because of enhancement in the spark energy, which leads to a higher temperature of the electrode. The gap voltage has a higher impact on TWR and raises it to an average of $0.0156 \mathrm{~g} / \mathrm{min}$, which is around nine times compared to the effect of discharge current. This massive jump in TWR is because of the direct relation between gap voltage and total energy of discharge in one spark. In contrast, the other control factors such as $\mathrm{T}_{\mathrm{ON}}, \mathrm{T}_{\mathrm{OFF}}$, and DP have minor impacts on TWR. For minimal TWR, gap voltage is the most significant control parameter.

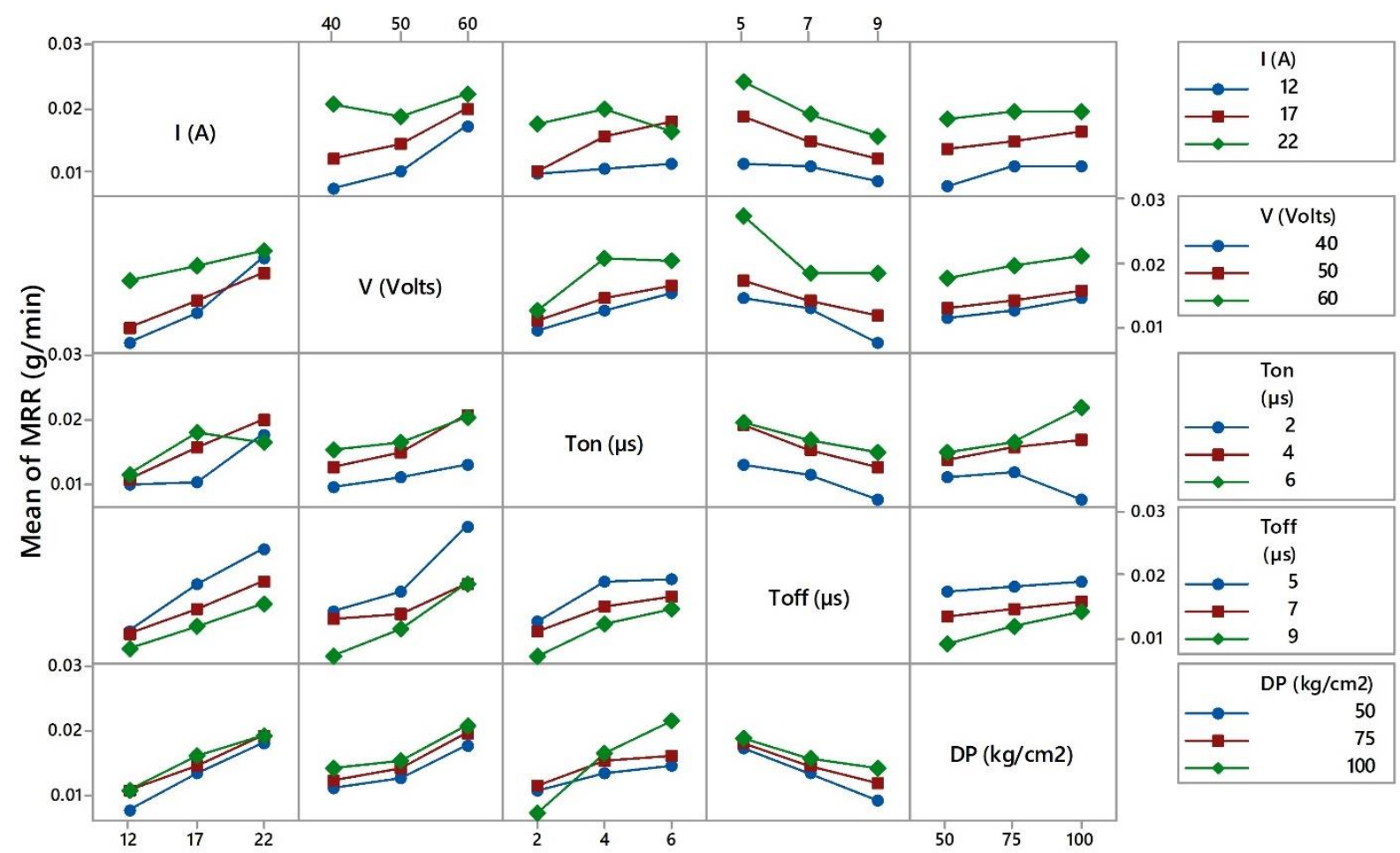

Figure 5 - Interaction plot of process parameters for MRR. 


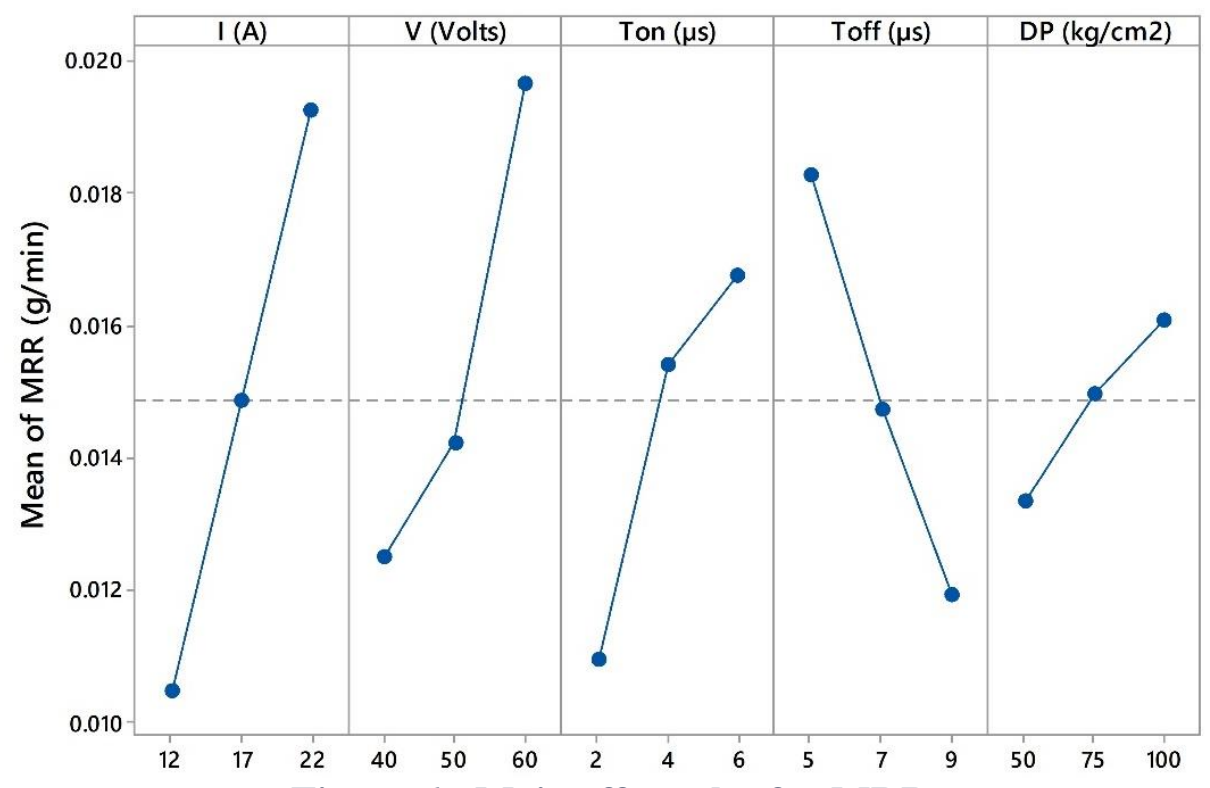

Figure 6 - Main effect plot for MRR.

Figure $9 \& 10$ show the interaction and main effect plot for DoT, respectively. These plots indicate that by increasing the discharge current and the gap voltage, the DoT increased by 10 \& $21 \%$, respectively, due to the spark's total discharge energy. By increasing $\mathrm{T}_{\mathrm{ON}}, \mathrm{T}_{\mathrm{OFF}}$, and DP, the value of DoT decreased by around 37, $11 \& 26 \%$, respectively, because of an increase in discharge time and cooling of the workpiece material. As DoT needs to be minimized, $T_{\text {ON }}$ is the most influencing process parameter followed by DP.

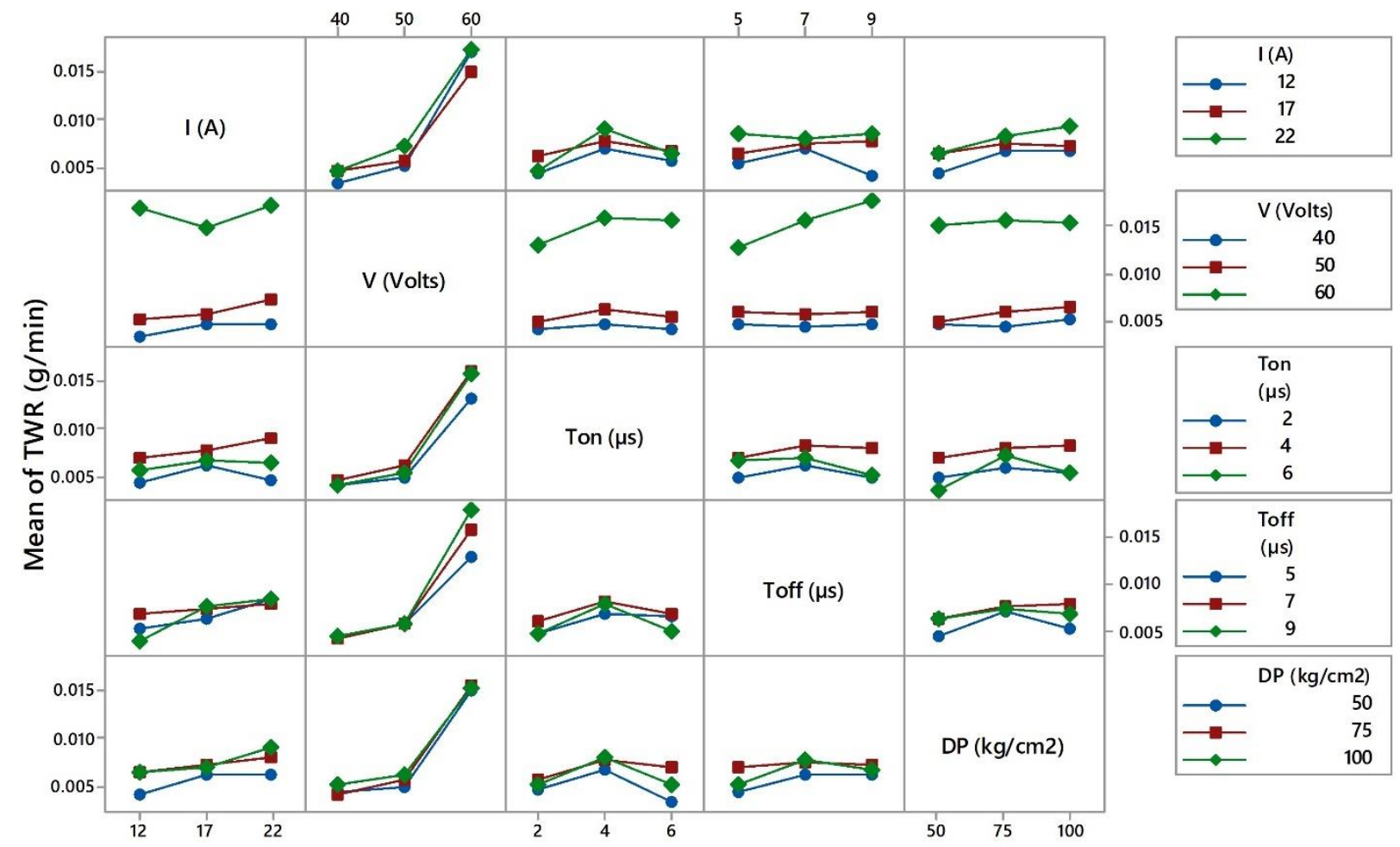

Figure 7 - Interaction plot of process parameters for TWR. 


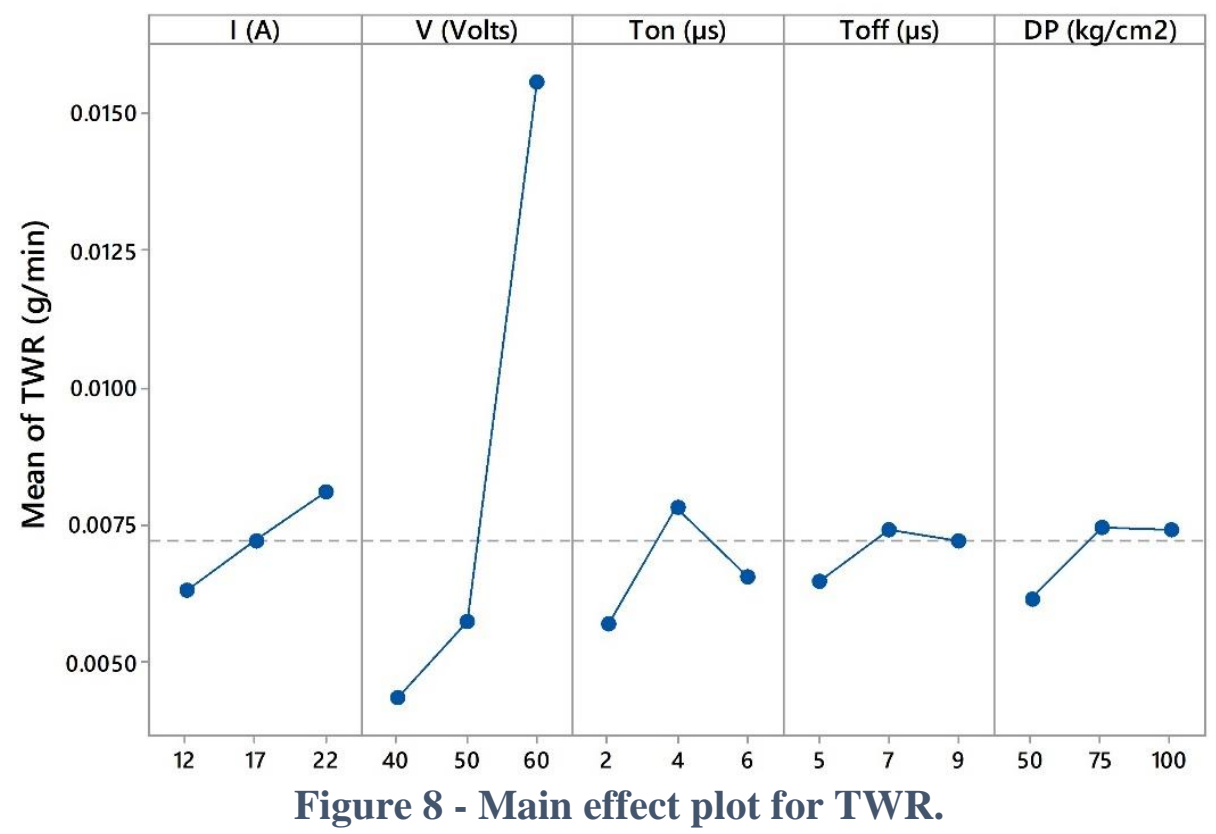

Figure 11, 12 \& 13 shows the surface and contour plots for MRR, TWR and DoT, respectively, as functions of the most significant control variable parameters (viz. viz. $\mathrm{V}$ and $\mathrm{T}_{\mathrm{ON}}$ ), at $\mathrm{I}=22 \mathrm{~A}$, $\mathrm{T}_{\mathrm{OFF}}=7 \mu \mathrm{s}$ and $\mathrm{DP}=100 \mathrm{~kg} / \mathrm{cm} 2$. Figure 11 indicates that the maximum value of MRR is 0.0277 $\mathrm{g} / \mathrm{min}$ at higher gap voltage $\&$ discharge time, and the minimum value is $0.0074 \mathrm{~g} / \mathrm{min}$ at lower gap voltage $\&$ discharge time. This variation occurs due to energy availability.

Figure 12 indicates that the maximum and minimum values of TWR are 0.0177 and 0.0033 $\mathrm{g} / \mathrm{min}$, respectively. Gap voltage has a more significant influence on it, whereas $\mathrm{T}_{\mathrm{ON}}$ has the most negligible impact. Maximum TWR is at a higher value of gap voltage as the energy received by the electrode from the spark will rise. Figure 13 indicates that the DoT has its maximum and minimum values of 0.032 and 0.01 radians, respectively. The DoT has a higher value nearer to the lower values of gap voltage and the discharge time, whereas it is low at higher values of gap voltage and discharge time. A minimum value will occur if the sparking will concentrate at the electrode's tip, leading to the material removal for getting the hole drilled.

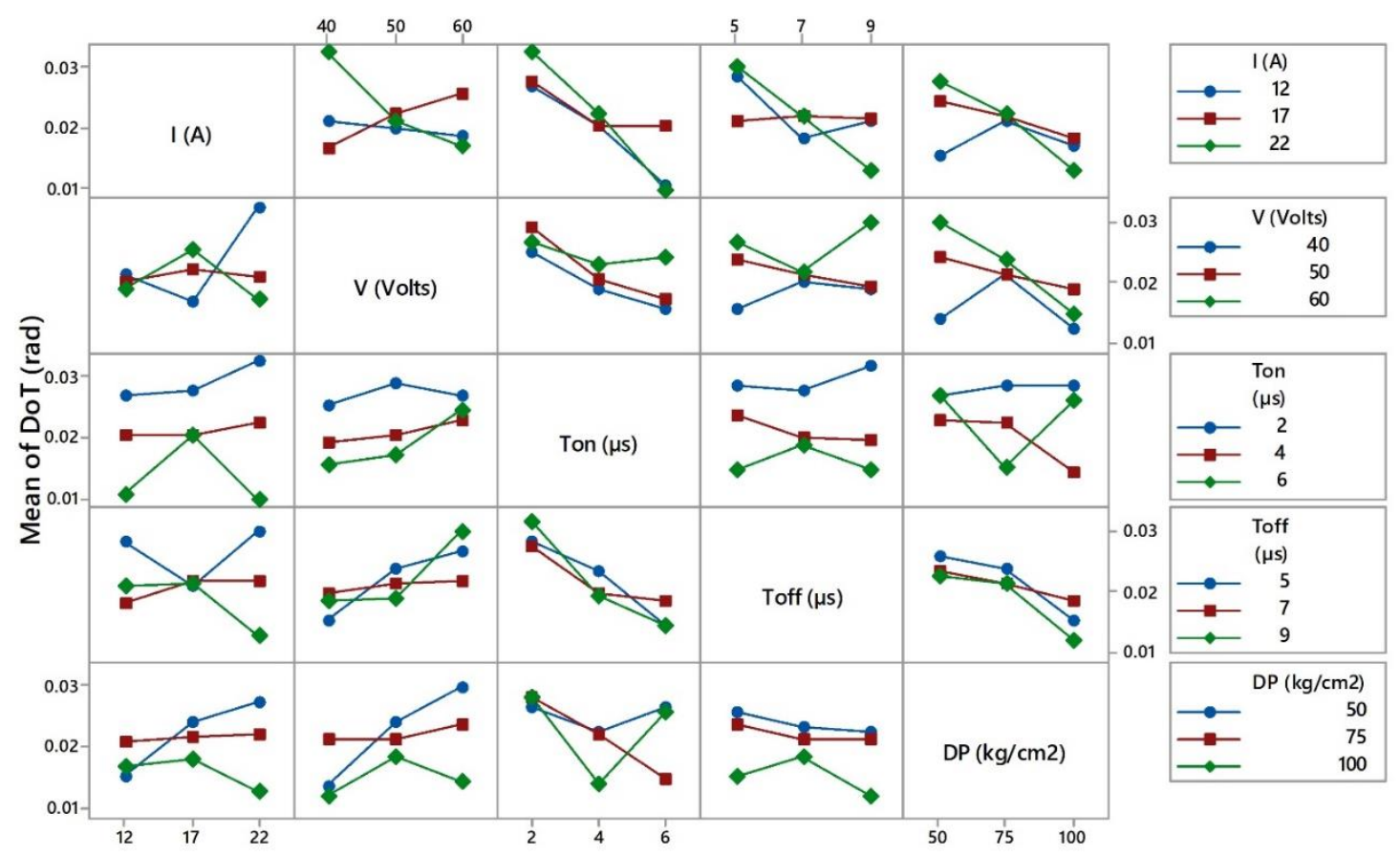

Figure 9 - Interaction plot of process parameters for DoT. 


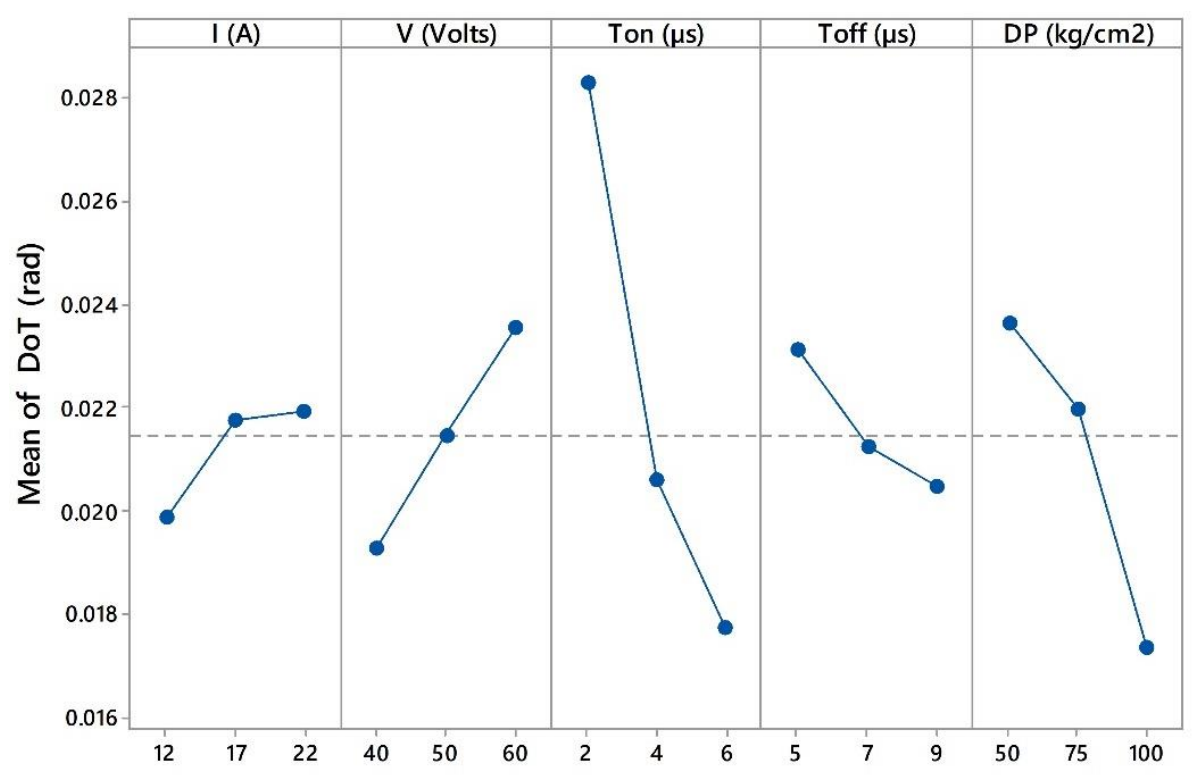

Figure 10 - Main effect plot for DoT.

A confirmation test has been carried out to validate performance characteristics' improvement after obtaining optimum control parameters of EDM, and optimal value has been evaluated using Equation 13.

$\eta_{\text {est }}=\eta_{m}+\sum_{1}^{n}\left(\eta_{i}-\eta_{m}\right)$

Where $\eta_{\mathrm{m}} \& \eta_{\mathrm{i}}$ are the mean and $\mathrm{i}^{\text {th }}$ response, respectively.

$\mathrm{L}_{23}$ is found as the optimum conditions for maximizing MRR and minimizing TWR \& DoT from the GRG and its order simultaneously. The optimum combination of process control variable parameters are $\mathrm{I}_{3}, \mathrm{~V}_{2}, \mathrm{~T}_{\mathrm{ON} 3}, \mathrm{~T}_{\mathrm{OFF} 2} \& \mathrm{DP}_{2}$, and their responses are MRR $0.0164 \mathrm{~g} / \mathrm{min}$, TWR 0.0064 $\mathrm{g} / \mathrm{min}$, DoT 0.0097 radians \& SNR of GRG $-2.8069 \mathrm{~dB}$.

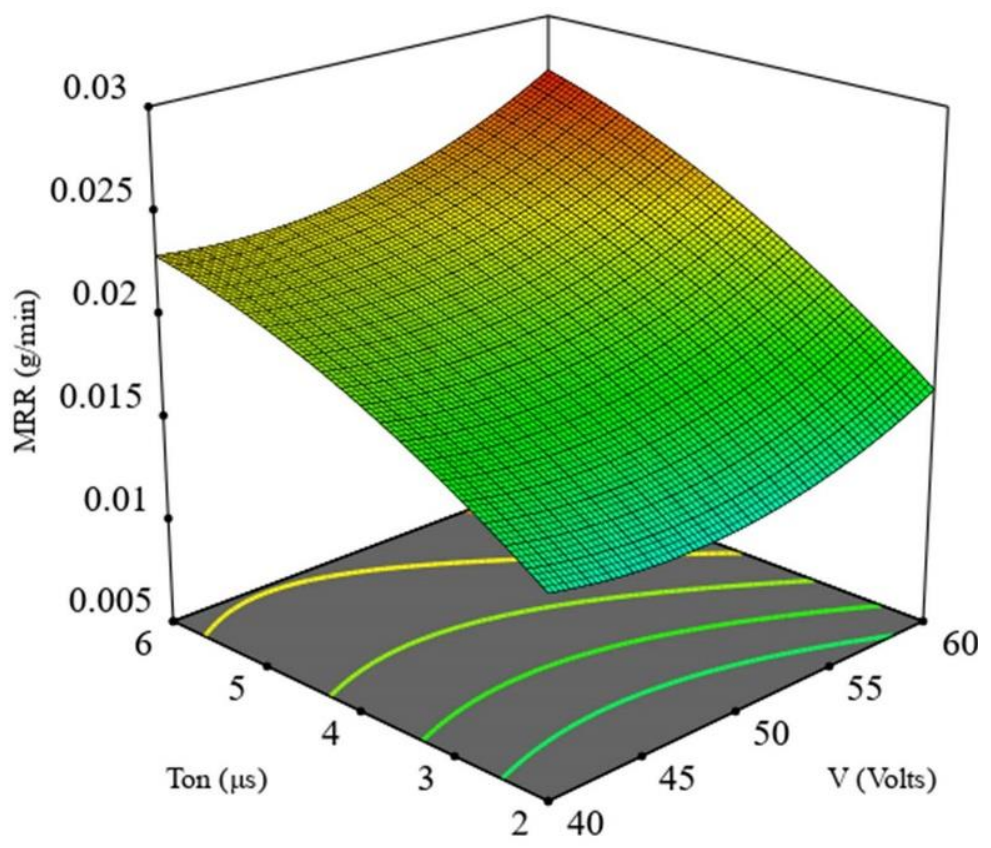

Figure 11 - Surface and contour plots for MRR. 


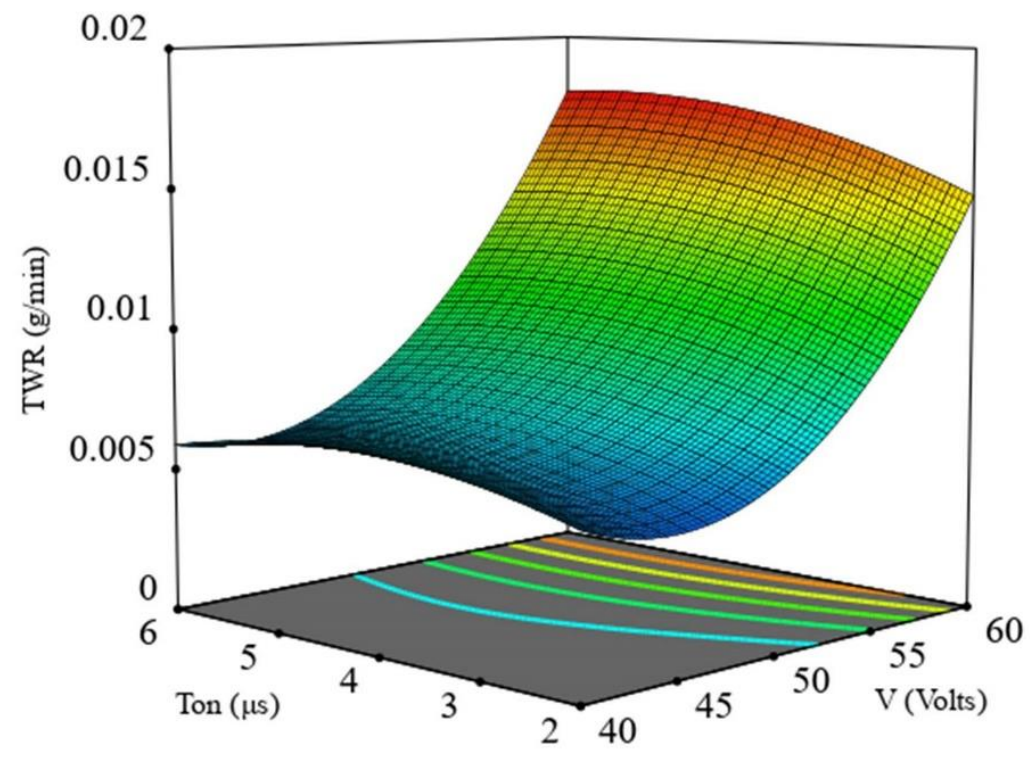

Figure 12 - Surface and contour plots for TWR.

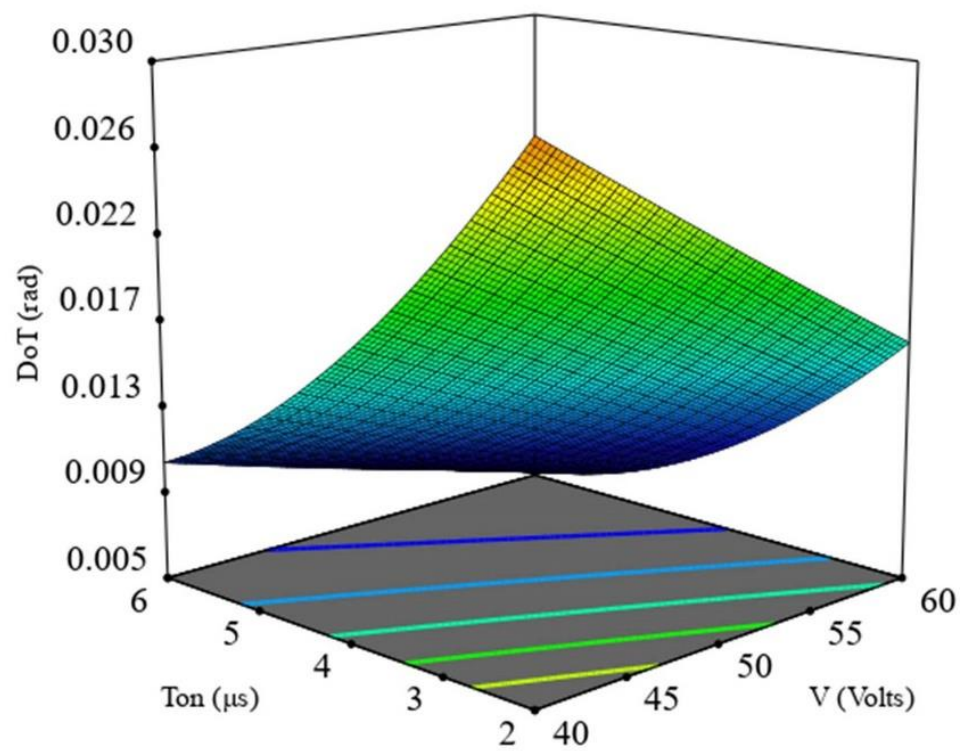

Figure 13 - Surface and contour plots for DoT.

It has been observed that the optimum setting of input control parameters, comparing with the initial set, that there are improvements in the quality characteristics. MRR was raised by $49.1 \%$, where TWR and DoT were lowered by 4.5 and $43.3 \%$.

\section{Conclusions}

Based on the experimentation of EDM drilling on Nitinol SMA and its analysis using GRG assisted Taguchi for multi-response optimization of the quality characteristics (viz. MRR, TWR, and DoT), the following conclusions can be made:

i. Gap voltage and discharge time are the most significant process control variables.

ii. The optimum frame of parameters is higher discharge current (I) and time (TON) with average gap voltage $(\mathrm{V})$, charging time $\left(\mathrm{T}_{\mathrm{OFF}}\right)$ (higher than $\left.\mathrm{T}_{\mathrm{ON}}\right)$, and dielectric flushing pressure (DP).

iii. $\quad$ MRR, TWR, and DoT are improved by 49.1, 4.5, and $43.3 \%$, respectively, compared to the initial experiment. 


\section{References}

Ahmed, A., Lew, M. T., Diwakar, P., Kumar, A. S., \& Rahman, M. (2019). A novel approach in high performance deep hole drilling of Inconel 718. Precision Engineering, 56(January), 432-437. https://doi.org/10.1016/j.precisioneng.2019.01.012

Al-Amin, M., Abdul Rani, A. M., Abdu Aliyu, A. A., Abdul Razak, M. A., Hastuty, S., \& Bryant, M. G. (2020). Powder mixed-EDM for potential biomedical applications: A critical review. Materials and Manufacturing Processes, 00(00), 1-23. https://doi.org/10.1080/10426914.2020.1779939

Chakraborty, S., Sudhakar Dandge, S., \& Agarwal, S. (2019). Non-traditional machining processes selection and evaluation: A rough multi-attributive border approximation area comparison approach. Computers \& Industrial Engineering, 139(July 2019), 106201. https://doi.org/10.1016/j.cie.2019.106201

Datta, S., Bandyopadhyay, A., \& Pal, P. K. (2008). Grey-based taguchi method for optimization of bead geometry in submerged arc bead-on-plate welding. The International Journal of Advanced Manufacturing Technology, 39(11-12), 1136-1143. https://doi.org/10.1007/s00170-007-1283-6

Deepan Bharathi Kannan, T., Pegada, R., Sathiya, P., \& Ramesh, T. (2018). A comparison of the effect of different heat treatment processes on laser-welded NiTinol sheets. Journal of the Brazilian Society of Mechanical Sciences and Engineering, 40(12), 562. https://doi.org/10.1007/s40430-018-1481-1

Gautam, G., \& Mishra, D. (2019). Evaluation of geometrical quality characteristics in pulsed Nd:YAG laser cutting of Kevlar-29/Basalt fiber reinforced hybrid composite using Grey relational analysis based on genetic algorithm. FME Transactions, 47(3), 560-575. https://doi.org/10.5937/fmet1903560G

HuuPhan, N., Muthuramalingam, T., Vu, N. N., \& Tuan, N. Q. (2020). Influence of micro size titanium powder-mixed dielectric medium on surface quality measures in EDM process. International Journal of Advanced Manufacturing Technology, 109(3-4), 797-807. https://doi.org/10.1007/s00170-020-05698-9

Jahan, M. P., Rahman, M., \& Wong, Y. S. (2011). A review on the conventional and microelectrodischarge machining of tungsten carbide. International Journal of Machine Tools and Manufacture, 51(12), 837-858. https://doi.org/10.1016/j.ijmachtools.2011.08.016

Kumar, D., Singh, N. K., \& Bajpai, V. (2020). Recent trends, opportunities and other aspects of micro-EDM for advanced manufacturing: a comprehensive review. Journal of the Brazilian Society of Mechanical Sciences and Engineering, 42(5), 1-26. https://doi.org/10.1007/s40430-020-02296-4

Kumar, S., Ghoshal, S. K., Arora, P. K., \& Nagdeve, L. (2020). Multi-variable optimization in die-sinking EDM process of AISI420 stainless steel. Materials and Manufacturing Processes, 00(00), 1-11. https://doi.org/10.1080/10426914.2020.1843678

Lin, J. L., \& Lin, C. L. (2002). The use of the orthogonal array with grey relational analysis to optimize the electrical discharge machining process with multiple performance characteristics. International Journal of Machine Tools and Manufacture, 42(2), 237244. https://doi.org/10.1016/S0890-6955(01)00107-9

Liu, J. F., Li, C., Fang, X. Y., Jordon, J. B., \& Guo, Y. B. (2018). Effect of wire-EDM on fatigue of nitinol shape memory alloy. Materials and Manufacturing Processes, 33(16), 1809-1814. https://doi.org/10.1080/10426914.2018.1512125

Majumder, H., \& Maity, K. (2018). Prediction and optimization of surface roughness and micro-hardness using grnn and MOORA-fuzzy-a MCDM approach for nitinol in WEDM. Measurement, 118, 1-13. https://doi.org/10.1016/j.measurement.2018.01.003

Mwangi, J. W., Bui, V. D., Thüsing, K., Hahn, S., Wagner, M. F. X., \& Schubert, A. (2020). Characterization of the arcing phenomenon in micro-EDM and its effect on key mechanical properties of medical-grade Nitinol. Journal of Materials Processing 
Technology,

275(March

2019),

116334.

https://doi.org/10.1016/j.jmatprotec.2019.116334

Mwangi, J. W., Weisheit, L., Bui, V. D., Zanjani, M. Y., \& Schubert, A. (2018). Influence of Micro-EDM on the Phase Transformation Behaviour of Medical-Grade Nitinol. Shape Memory and Superelasticity, 4(4), 450-461. https://doi.org/10.1007/s40830-018-001951

Sarmah, A., Kar, S., \& Patowari, P. K. (2020). Surface modification of aluminum with green compact powder metallurgy Inconel-aluminum tool in EDM. Materials and Manufacturing Processes, 35(10),

1104-1112. https://doi.org/10.1080/10426914.2020.1765253

Sharma, A., \& Yadava, V. (2018). Experimental analysis of Nd-YAG laser cutting of sheet materials - A review. Optics and Laser Technology, 98, 264-280. https://doi.org/10.1016/j.optlastec.2017.08.002

Sharma, P., Singh, S., \& Mishra, D. R. (2014). Electrical Discharge Machining of AISI 329 Stainless Steel Using Copper and Brass Rotary Tubular Electrode. Procedia Materials Science, 5, 1771-1780. https://doi.org/10.1016/j.mspro.2014.07.367

Shin, M.-C., Kim, Y.-S., Cheong, H.-G., \& Chu, C.-N. (2019). Performance of a TR-iso-pulse generator in micro ED-drilling. Precision Engineering, June 2018, 0-1. https://doi.org/10.1016/j.precisioneng.2019.01.013

Singh, P. N., Raghukandan, K., \& Pai, B. C. (2004). Optimization by Grey relational analysis of EDM parameters on machining $\mathrm{Al}-10 \% \mathrm{SiCP}$ composites. Journal of Materials Processing Technology, 155-156(1-3), 1658-1661. https://doi.org/10.1016/j.jmatprotec.2004.04.322

Singh, R., Dvivedi, A., \& Kumar, P. (2020). EDM of high aspect ratio micro-holes on Ti-6Al4V alloy by synchronizing energy interactions. Materials and Manufacturing Processes, 35(11), 1188-1203. https://doi.org/10.1080/10426914.2020.1762207

Sonawane, S. A., \& Kulkarni, M. L. (2018). Optimization of machining parameters of WEDM for Nimonic-75 alloy using principal component analysis integrated with Taguchi method. Journal of King Saud University - Engineering Sciences, 30(3), 250-258. https://doi.org/10.1016/j.jksues.2018.04.001

Taguchi, G., \& Phadke, M. S. (1989). Quality Engineering through Design Optimization. In Quality Control, Robust Design, and the Taguchi Method (pp. 77-96). Springer US. https://doi.org/10.1007/978-1-4684-1472-1_5

Tripathy, S., \& Tripathy, D. K. (2016). Multi-attribute optimization of machining process parameters in powder mixed electro-discharge machining using TOPSIS and grey relational analysis. Engineering Science and Technology, an International Journal, 19(1), 62-70. https://doi.org/10.1016/j.jestch.2015.07.010

Vidyasagar, K. E. C., Rana, A., \& Kalyanasundaram, D. (2020). Optimization of laser parameters for improved corrosion resistance of nitinol. Materials and Manufacturing Processes, 1-9. https://doi.org/10.1080/10426914.2020.1784926 